\title{
Innovative Mathematical Methods and New Software Applications for Cost-Effective, Profitable and Environmentally Friendly Freight Transport
}

\author{
György Kovács \\ University of Miskolc, Institute of Logistics, Hungary
}

Received: 30 May 2018

Accepted: 27 July 2018

\begin{abstract}
Due to the optimization and efficiency improvement of freight transportation, fuel consumption and environmental damage are reduced. Furthermore, if companies are more profitable, they can afford to invest in environmentally friendly technologies. Consequently, transportation will become more economic, sustainable and environmentally friendly.

Three innovative methods and three new software applications have been developed to provide profitable and sustainable transportation:

1) Structure of key performance indicators and software for continuous evaluation of transport activity. If we can measure the performance, we can improve it in the future.

2) Calculation method and software for precise determination of the total prime cost of a given transportation order. It is significant, because knowing the prime cost, the carrier can calculate the expected profit. Since the transport fee includes the profit, profitable operation can be ensured.

3) Optimization method and software to optimize the fuel cost. At first by determining the optimal, most cost-effective petrol station (depending on the unit fuel price and distance of the potential petrol stations). Then the optimal amount of fuel has to be calculated, i.e. the exact amount needed, plus a safe margin to cover unexpected events.

Recently the above-mentioned activities have been unsupported by software, therefore this research is original.
\end{abstract}

Keywords: road transport; performance evaluation; prime cost; fuel cost; software development

*e-mail: altkovac@uni-miskolc.hu 


\section{Introduction}

Transportation is the most expensive and environmentally damaging activity in the supply chain, and fuel cost is the highest cost component of transportation [1]. The volume of road freight transport in Europe is approximately $80 \%$ of the total freight transport volume [2]. The forecasts of the experts show that the intensity of road freight transportation is likely to constantly increase in the future.

Due to the growing global competition, more complex and longer supply chains, increasing consumption and changing customer demands the optimization of road freight transport processes and reduction of transport costs are essential for transportation companies to maintain and increase their competitiveness.

At the same time there is a global tendency that the above-mentioned economic changes are causing increasing environmental damage and high noise and air pollution $[3,4]$.

The environmental damage is a global problem, therefore the establishment of sustainable and environmentally friendly transportation is also an important goal.

Every economically developed country defines directives and regulations to reduce these negative impacts on the environment and to establish a sustainable economy. If enterprises cannot comply with regulations, they cannot operate.

Based on the above-mentioned negative impacts on the environment, the intention of the European Union is to reduce the ratio of road freight transportation, increase the ratio of multimodal transportation and use sustainable transport systems by application of environmentally friendly technologies.

This research is both relevant and important because it is a global problem that requires a fast solution to which scientific research can also contribute.

Basically, there are two ways for science to support sustainable and environmentally friendly transportation. The first is developing and producing environmentally friendly technologies and equipment (e.g., high-tech engines). Furthermore, science also can support the cost-effective, profitable and sustainable operation of transport companies by efficiency improvement methods and decision-supporting software applications based on mathematical methods and models. These efficiency improvement methods result in one part on reducing fuel consumption and environmental damage. On the other hand, if the companies that are able to achieve higher profits can afford to invest in environmentally friendly technologies and fleets of new vehicles, this also results in the reduction of environmental damage. Although environmentally friendly technologies are available, if transport companies lack capital they cannot afford to purchase them.

Based on three innovative theoretical methods, I developed three new and original decision- supporting software applications to support costeffective and profitable operation, which is essential for environmentally friendly and sustainable freight transportation. Fuel consumption and emissions can be reduced by the application of the developed software applications.

1) Developing a structure of key performance indicators (KPI) and software for continuous performance measurement and evaluation of freight transport activity.

First I defined the structure of the four most commonly used transport indicators (transport method utilization, time utilization, weight of transported goods and fuel consumption) and worked out the calculation methods for these KPIs. Based on the elaborated transport indicators, evaluation software was developed. The software application is able to evaluate indicators for a selected examination time interval numerically and graphically. If we can measure the historical and current performance of transport activities, we can improve the efficiency of the processes in the future.

Optimizing the freight transport activity leads to the improvement of the KPIs; therefore, optimized utilization of vehicle fleet capacity, efficient transport coordination, optimal design of transport trips and minimal fuel consumption will be achieved. Consequently, fuel consumption and environmental damage can be reduced.

2) Calculation method and software for precise and fast determination of the total prime cost of a given transport order. The first step was to define the cost components of the prime cost function and elaborate the calculation methods for these components. This is very important, because if the prime cost can be defined precisely before the carrier gives a quotation to the customer, the carrier can calculate the expected profit. As the transport fee includes the expected profit, it can be ensured and losses can be eliminated.

Based on the elaborated method, new decisionsupporting software was developed for the profitable fulfillment of transport trips.

This method and software are innovative, because nowadays in practice the definition of the transport fee depends on the individual estimation of the transport operators; hence it can result in losses if the bid for an order is lower or higher compared to the market price.

The precision of the elaborated calculation method and the developed software was validated by comparing the amount calculated by the software and real costs of transport orders.

The method and the software was developed to show that the software automatically takes into consideration the following aspects: the determination of the optimal transport route, optimal design of transport trips, minimal fuel consumption, minimization of empty haulage, optimized utilization of vehicle fleet capacity and human resources. By the application of the above-mentioned efficiency improvement methods, 
fuel consumption and environmental damage can be reduced.

3) Optimization method and software to optimize the fuel costs in case of a given transport demand through selection of the optimal petrol station and calculation of the optimal volume of refilled fuel.

The software determines the optimal petrol station within a search zone, i.e. the one that provides the most cost-effective (minimal total cost) solution. Unit fuel prices are different at the different available petrol stations. The optimization method can determine whether refueling at a cheaper but farther petrol station or at an expensive but nearer petrol station is more costeffective.

The optimal quantity of the amount of refilled fuel can also be defined by the method, i.e. the volume that is needed and sufficient to complete the given transport order, including a certain amount of fuel to cover unexpected events (the additional consumption of the vehicle resulting from detours or traffic accidents, etc.). Less than the optimal amount of refilled fuel results in extra unnecessary refueling. A higher amount of fuel refilled near the end of the route is also a waste, because the cheapest fuel is available at the depot of the carrier.

The developed method and software are innovative and original, because nowadays in practice the decisions of where and how much to refuel have not been supported by software at the transport firm; they depend on the individual decision of the driver.

The fuel cost reduction resulting from the application of the developed calculation method and software (optimal decision) was validated in a case study by comparison of the driver's wrong decision based on an estimation.

Application of the calculation method and the software results in significant fuel cost savings, which increase the profit of the company.

The method and the software was developed so that the software automatically takes into consideration the following aspects: monitoring and tracking of the vehicle, minimal fuel consumption and fuel cost, optimal design of transport route and transport trips, minimization of empty haulage, optimized utilization of vehicle fleet capacity, efficient transport coordination by the application of information and communication technologies. By the application of the above-mentioned efficiency improvement methods, fuel consumption and environmental damage can be reduced.

The above-mentioned three software applications are customizable, easy to use, very cost-effective and can be used widely in practice because even small and medium-sized enterprises (SMEs) can afford them, instead of having to invest in expensive enterprise resource planning (ERP) systems.

The software applications were successfully implemented by carriers.

\section{Materials and Methods}

The goal of my research was to develop innovative mathematical methods and models for providing profitable, sustainable and environmentally friendly transportation. Based on these innovative theoretical methods I developed new and original decisionsupporting software applications.

These efficiency improvement methods and software have resulted in the reduction of fuel consumption and environmental damage.

Although the existing literature often discusses the topic of cost-effective transportation, there is a gap in the literature in the following three fields that I researched: evaluation of road freight transport activity, total prime cost calculation and fuel optimization of road transportation. It can be concluded that there are hardly any materials available in these research topics, so these topics are absolutely new and original.

In the past few years I have completed several research and development projects for transport companies, so I have practical experience in the field of transportation. Furthermore, before the development of the methods and software applications I consulted with the experts of transport companies about their needs. Therefore, the developed methods and software applications can be used widely in practice.

The developed software applications are new and original, because recently the above-mentioned activities are unsupported by software.

I evaluated a lot of literature relating to the research topic, which provided the theoretical background of the recent study.

The literature often discusses general performance measurement methods and often uses KPIs [5], logistics performance indicators [6] and KPIs for different transport modes [7].

Many studies have been published relating to the general characteristics and the cost components of road freight transport [8-10].

There is a great deal of literature discussing the general logistics costs [11-13], and logistics literature rarely deals with the introduction of transport cost components $[14,15]$.

The most important goals of the organization of the road freight transport are the minimization of specific transport cost per unit load and minimization of transport lead time [16-18].

There are three different organizational methods in the case of road transportation: simple trips, shuttle trips and round trips [19-21]. The most common form of organizing international road transportation is the round trip.

The existing literature often discusses route optimization [22, 23] and optimizing transport trips and networks $[16,18,20]$, but there is a gap in the literature in the field of fuel optimization of road freight transportation. There is also a gap in the literature 
regarding how road freight transportation will become not only cost-effective and profitable, but at the same time sustainable and environmentally friendly.

\section{General Methods for Efficiency Improvement} of Sustainable Freight Transportation

\section{Current Tendencies in Freight Transportation}

- Supply chains are becoming more complex and longer. The volume of freight transportation is constantly increasing.

- Customer demands are continuously changing. Customers expect shorter shipping times and higher transportation quality [1].

- Applying environmentally friendly and sustainable technologies for freight transportation is an important goal, as well as air and noise pollution reduction, green waste management and recycling.

- The proportion of road freight transportation is the highest among the transport modes in Europe (road, rail, water, pipeline and air), and forecasts show that the intensity is expected to increase constantly in the future $[2,15]$.

\section{General Methods for Efficiency Improvement of Sustainable Road Freight Transportation}

By the application of efficiency improvement methods, fuel consumption and environmental damage will be reduced. Efficiency improvement methods are the following:

- More effective cooperation and synchronization between transport modes (road, rail, water and air).

- More effective transport coordination, optimal design of transport trips, minimization of empty haulage $[15,19]$

\section{Indicators relating to: 1$)$ individual vehicles, 2) group of vehicles, 3 ) all of vehicles and 4) transport trips \\ 1. Transport way utilization \\ - Way with freight \\ - Way without freight \\ - Way with freight/Total way

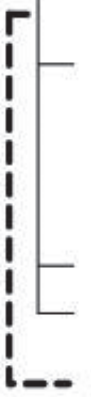 \\ 2. Time utilization \\ — Working days \\ - Non working days \\ Working days / Sum of days \\ 3. Weight of transported goods \\ 4. Fuel consumption (total/specific) \\ For a selected examination time interval}

Fig. 1. Structure of transport indicators
- Optimized utilization of vehicle fleet capacity and human resources.

- Application of information and communication technologies.

- Better monitoring and tracking.

- Application of the results of scientific research at companies (decision-supporting software applications based on mathematical models) $\rightarrow$ more cost-effective and profitable operation of transport companies $\rightarrow$ higher income and higher profit for the companies $\rightarrow$ transport companies can afford to invest in environmentally friendly technologies $\rightarrow$ higher income for the companies, increasing tax revenue for the government $\rightarrow$ government can provide financial support for companies for investment in environmentally friendly technologies $\rightarrow$ reduction of environmental damage, establishment of sustainable transportation [1].

\section{Results and Discussion}

Development of Structure of KPIs and Software for Continuous Performance Measurement and Evaluation of Freight Transport Activity

\section{Reason and Goal of the Research}

Monitoring KPIs is an efficient tool for performance measurement of transport activity and provides high transparency of the processes, since processes that can be measured can be improved.

The goals of performance measurement are the following:

- Continuous evaluation of historical and current data in order to improve the efficiency of transport processes in the future.

- Identify weaknesses of the transport and business processes at the company.

- Determine improvement opportunities and goals at the enterprises.

- Support strategic and operative decision making.

\section{Elaboration of Structure of KPIs for Evaluating Road Transport Activity}

I elaborated upon the structure of the 4 most important and commonly used transport indicators: 1) transportation method, 2) time utilization, 3) weight of transported goods, 4) fuel consumption, along with the calculation methods for these indicators (Fig. 1). These KPIs are needed and are sufficient to evaluate freight transport activity.

The above-mentioned indicators relating to 1) individual vehicles, 2) groups of vehicles (camions, light trucks), 3) all vehicles and 4) transport trips. 


\section{Calculation Methods for KPIs, Evaluation Software Application}

Evaluation software was developed based on the elaborated structure of transport KPIs (Fig. 1). (Calculation methods for the elaborated KPIs will be described simultaneously with the software applications in the following subsections.)

The software application is able to evaluate indicators defined in Fig. 1 for a selected examination time interval numerically and graphically. A database including historical data used for evaluation was provided by a forwarding company.

The user has to select the following options of the software:

- KPIs/KPI groups to be evaluated (Fig. 1).

- Vehicle: 1) individual vehicles, 2) vehicle groups (e.g., camions or light trucks), 3) all of vehicles or 4) transport trips to be evaluated.

- Selected examination time interval.

The result of the evaluation in the case of 4 KPIs will automatically appear on the screen of the software for the selected examination time interval numerically and graphically (see Fig. 2).

The evaluation of all KPIs is visualized graphically by bar charts. The numerical evaluation of the KPIs is listed on the screen by the following statistical data: median, deviation, minimum, maximum, deviation/ median, max/median, min/median, etc. (see Fig. 2).

The software provides the possibility of evaluating the above-mentioned 4 KPIs relating to 1) individual vehicles, 2) groups of vehicles (camions, light trucks),
3) all vehicles and 4) transport trips in different examination time intervals.

Results of the software application: the evaluation of the historical transport data results in the efficiency improvement and optimization of the processes in the future, and more economical and sustainable freight transportation. KPIs are improving: time- and transport way utilization of vehicles and transport trips are increasing, empty haulage is reduced, fuel consumption is reduced, etc.

Calculation methods for the elaborated 4 KPIs will be described simultaneously with the software applications in the next part. (Due to the page limit I will show only 1 screen of the evaluation software.)

\section{Transport Method Utilization of Vehicles or Transport Trips}

Transport method utilization of the above-mentioned vehicle categories and transport trips can be calculated:

$$
\eta_{T W i, j}=\frac{L_{U i, j}}{L_{U i, j}+L_{N U i, j}} \cdot 100[\%]
$$

...where $\eta_{T W i, j}$ is transport method utilization; $L_{U i, j}$ is length of the useful (with useful freight) transport route $(\mathrm{km}) ; L_{N U i, j}$ is the length of non-useful (without freight) transport method $(\mathrm{km})$.

Fig. 2 shows an example for graphical and numerical evaluation of total transport distance indicators in an examined time interval.

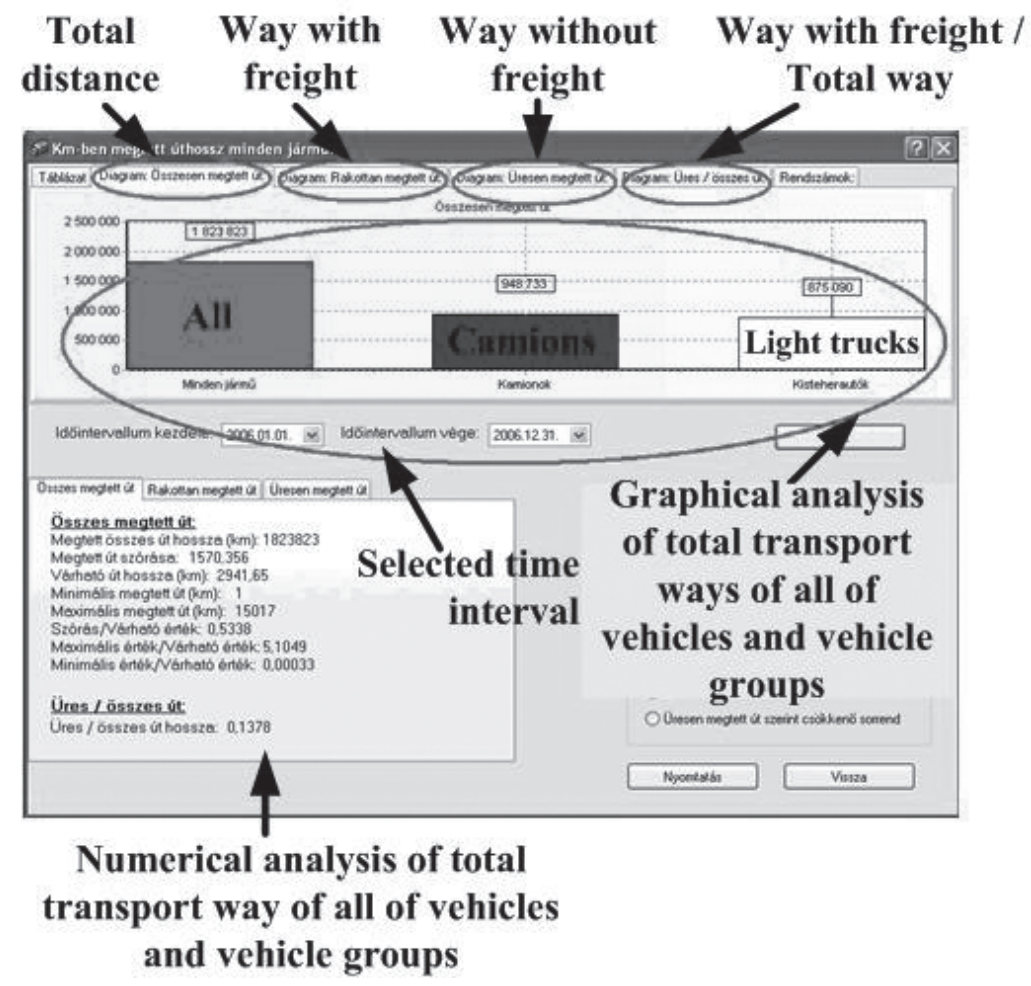

Fig. 2. Transport distances of vehicles. 
The software is able to achieve graphical and numerical evaluation of data relating to total distance, the method of freight, the method without freight and the method with freight/total way in case of vehicles or transport trips for the selected examination time interval.

\section{Time Utilization of Vehicles or Transport Trips}

Time utilization of the above-mentioned vehicle categories and transport trips can be calculated:

$$
\eta_{T i, j}=\frac{T_{W i, j}}{T_{W i, j}+T_{N W i, j}} \cdot 100[\%]
$$

...where $\eta_{T i, j}$ is time utilization of vehicles or transport trips; $T_{W i, j}$ is working days (time that vehicles are used for transportation) of vehicles, or transport trips (day); $T_{N W i, j}$ is non-working days (time that vehicles are not used for transportation) of vehicles, or transport trips (day); $i$ is the index relating to vehicles (can be individual vehicles, groups of vehicles or all vehicles); and $j$ is the index relating to transport trips.

The software is able to complete graphical evaluation (by bar chart) and numerical analysis (by statistical data) of data relating to working days, non-working days and sum of working days in the case of the abovementioned vehicle categories or transport trips in the selected examination time interval. Furthermore, the software is also able to evaluate numerically the ratio of the previously mentioned values.

\section{Weight of Goods Transported by Vehicles or in the Transport Trips}

The weight of transported freight is the most important and often used indicator for transport activities. It is significant, because the transported weight has an effect on fuel consumption, and furthermore on the elimination of empty haulage and optimization of transport trips.

The software is able to complete graphical and numerical evaluation of data relating to transported weights in the cases of vehicles or transport trips for a selected examination time interval.

\section{Total and Specific Fuel Consumption of Vehicles or in Transport Trips}

Specific fuel consumption can be calculated by the following equation:

$$
\eta_{F i, j}=\frac{Q_{T i, j}}{L_{T i, j}} \cdot 100\left[\frac{\text { liter }}{\mathrm{km}}\right]
$$

...where $\eta_{F i, j}$ is specific fuel consumption; $Q_{T i, j}$ is total fuel consumption of vehicle, or in a given transport trip in the selected time interval (liters); and $L_{T i, j}$ is the total transport route of vehicle, or in the given transport trip in the selected time interval (km).

The software is able to achieve graphical and numerical evaluation of data relating to total fuel consumption and specific fuel consumption in the case of vehicles or transport trips for the selected examination time interval.

\section{Calculation Method and Software for Determining the Total Prime Cost}

\section{Reason and Goal of the Research}

Nowadays in practice the calculation of transport fee has not been supported by software at transport companies, and it depends only on the individual estimation of the transport operator. This price estimation is based on historical transport data, which can result in inaccurate fee calculation. If the price offer is lower than its prime cost, a profit will not be realized. Otherwise, if the offer is higher than the market price, the business will not be realized and the company will not be competitive.

The goal of the research was to define a precise and fast calculation method for the total prime cost of a given transport demand, which can ensure a profit.

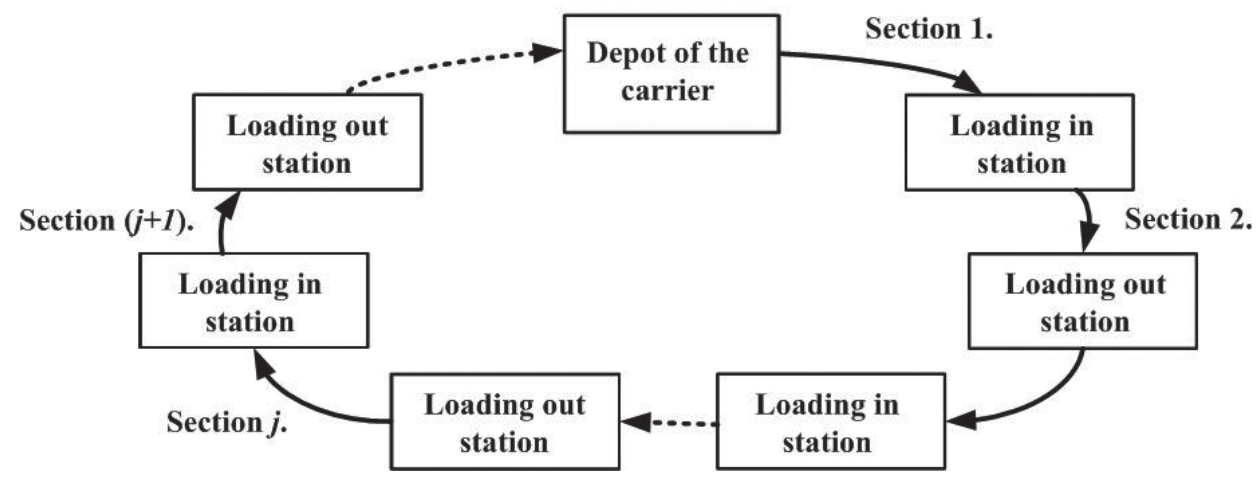

Fig. 3. Introduction of a road transport trip. 


\section{Prime Cost Calculation Method for Road Freight Transport Trips}

The most common form of organizing international road freight transportation is the round trip (Fig. 3). During the transport trip the vehicle departs from the depot of the transport company and goes to the first load-in station (where the goods are loaded), then it proceeds to the load-out station (where the goods are unloaded). Then it goes to the next loading station and to the next unloading station, etc. Finally, the vehicle goes to the depot of the carrier.

In calculating the transport, trips $(i)$ are divided into transport sections $(j)$. A section means the path between load-in and load-out stations $(j=1 \ldots N)$. The costs of the different sections depend on the characteristics of the transport vehicles, weight of transported goods and topography.

Firstly, the total prime cost function of a transport order and then the cost components of it were defined.

\section{Total Prime Cost}

Total prime cost of the $i$-th transport trip $\left(C_{P i}\right)$ can be calculated:

$$
C_{P i}=\sum_{j=1}^{N} C_{F i j}+C_{W T i j}+C_{A i j}+C_{W i j}+C_{O i j[\text { euro] }}
$$

...where $C_{F i j}$ is fuel cost; $C_{W T i j}$ is cost of waiting time; $C_{A i j}$ is additional extra costs; $C_{W i j}$ is labor cost of drivers; and $C_{O i j}$ is operational costs.

Indices used in the following mathematical formulation are: $i$ - road transport trip and $j$ - road transport section.

\section{Cost Components of the Prime Cost}

- Fuel cost

The fuel cost of a transport demand:

$$
C_{F i j}=c_{F i j} \cdot L_{i j} \quad \text { [euro] }
$$

... where $C_{F i j}$ is specific cost [euro/ $\mathrm{km}$ ] and $L_{i j}$ is distance of the section $[\mathrm{km}]$.

The specific cost can be defined by Eq. (6):

$$
c_{F i j}=c_{L e}\left[f_{e}+\varepsilon_{i j}^{T} \cdot f_{e}+\varepsilon^{L} \cdot m_{i j}\right][\text { euro/km] }
$$

...where $c_{L e}$ is unit fuel price [euro/liter]; $f_{e}$ is fuel consumption in case of an empty vehicle [liter $/ \mathrm{km}] ; \varepsilon^{T}{ }_{i j}$ is correction factor depending on topographical conditions (mountainous or flat); $\varepsilon^{L}$ is correction factor for loading conditions (every additional ton of transported goods results in extra fuel consumption) $\left[\frac{\text { liter }}{\text { ton } \mathrm{km}}\right]$; and $m_{i j}$ is the weight of transported goods [ton].

- Cost of waiting time

The cost of waiting time of a transport section:

$$
C_{W T i j}=c_{W T i j} \cdot\left(T_{L i j}+T_{W i j}+T_{R i j}+T_{S i j}\right) \text { [euro] }
$$

...where $C_{W T i j}$ is specific waiting cost [euro/hour]; $T_{L i j}$ is lead time of load-in and load-out activities [hour]; $T_{W i j}$ is waiting for load-in and -out activities [hour]; $T_{R i j}$ is waiting time due to daily break and rest requirements (according to European AETR agreement) [hour]; and $T_{S i j}$ is waiting time due to driving bans [hour].

\section{- Additional extra costs}

Total additional cost of a transport section:

$$
C_{A i j}=C_{A R i j}+C_{A P i j}+C_{A D i j}[\text { euro] }
$$

...where $C_{A R i j}$ is the motorway fee; $C_{A P i j}$ is the parking fee; and $C_{A D i j}$ is the fee for documentation, licenses, permissions, etc.

- Labor cost of drivers

The drivers' salary:

$$
C_{W i j}=c_{i j} \cdot T_{i j}[\text { euro] }
$$

...where $c_{j}$ is specific labor cost of a driver [euro/hour] and $T_{i j}$ is total lead time of a transport order [hour].

- Operational costs of vehicles

Operational and maintenance costs (taxes, maintenance, assurance, etc.) of a transport order:

$$
C_{O i j}=c_{O} \cdot \varepsilon_{O} \cdot T_{i j} \text { [euro] }
$$

...where $c_{o}$ is specific operational cost of vehicles [euro/hour]; $\varepsilon_{o}$ is the correction factor of different vehicles; and $T_{i j}$ is the lead time of achievement of a transport order [hour].

\section{Software Development for Prime Cost Calculation of Road Transport Demands}

Based on the elaborated method decision-supporting software was developed to define the prime cost of a given transport order. The software was developed in Delphi development environment.

Before the development of the method and software application I consulted with the experts of transport companies about their needs. Method and software were developed especially for SMEs, which generally can't afford to buy expensive ERP systems.

Further advantages of the software are that it absolutely suits the customer demands, is very costeffective and it can provide a fast and precise calculation based on a minimal number of input data. 
The developed software was successfully implemented at a carrier.

- The software provides the following possibilities:

1) "Database" for input and modifying data

2) "Calculation" of prime cost of transport demands

3) "Archive data" for listing and checking of previous calculations

1. In the "Database" menu the user can define the most important data relating to

- $\quad$ Available vehicles (e.g., specific fuel consumption, specific operational and maintenance costs)

- $\quad$ Actual unit fuel prices

- Motorway tolls in different countries, etc.

2) In the "Calculation" menu the user can define the most important data relating to the transport demand to be calculated.

Firstly, the user has to select the vehicle for the transport order. The basic characteristics of the vehicle (saved in a database, e.g., specific fuel consumption, maximal loading capacity, etc.) will automatically be taken into consideration during the calculation.

After that the transport section (given order), the parameters of the transport order have to be defined (Fig. 4). The identifier of the road section and the round trip, the length of transport sections and the topographical conditions and the weight of goods to be transported have to be defined.

Because of the difference in motorway tolls of different countries, the countries and distance of motorways have to be defined for all transport orders (Fig. 4). The waiting times ("stop - other reason") can also be given, because this time is also a cost. The total lead time of the total transport way is also calculated by the software, so the minimum break and rest periods are automatically calculated ("stops according to AETR"). The exchange rate of the HUF/EUR can be also given, so the cost components can be listed in Euro and HUF currencies. The number of drivers can also be given, so the labor cost is calculated based on it.
After the definition of the data needed for the prime cost calculations, the results (the different cost components (given by Eq. (5-10)) and the total prime cost (given by Eq. (4)) are listed for a given transport order on Fig. 5.

Based on this pre-calculation of the prime cost of a given transport order, the transport operator can supply a precise transport fee offer to the customers. The offered transport fee will not be under the prime cost or will not be much higher than the competitors' bid. Consequently, the risk and losses of the carrier can be eliminated.

3) In the "Archive data" menu the user can search in the earlier prepared plans and calculations. This can be very useful if the user wants to compare the earlier saved transport plans and the real data after carrying out transport orders.

\section{Validating the Efficiency and Precision} of the Elaborated Calculation Method and Software by Comparative Analysis

Comparative analysis was applied to validate the precision and reliability of the developed prime cost calculation method and software. The transport company provided its historical data for this examination.

In the case of three randomly selected archived transport orders (Task 1, Task 2 and Task 3) the following costs were compared: 1) real costs totaled after the transport trip, 2) prime costs pre-calculated by software and 3) prime costs pre-estimated by the transport operator based on the cost calculation method formerly used by the carrier (Table 1).

The difference between real cost and calculated cost in case of the examined three transport tasks is approximately $\pm 3 \%$, which is not significant, especially in the case of a long international road transport trip.

The difference between real cost and estimated cost is approximately $\pm 6-11 \%$, which is significant.

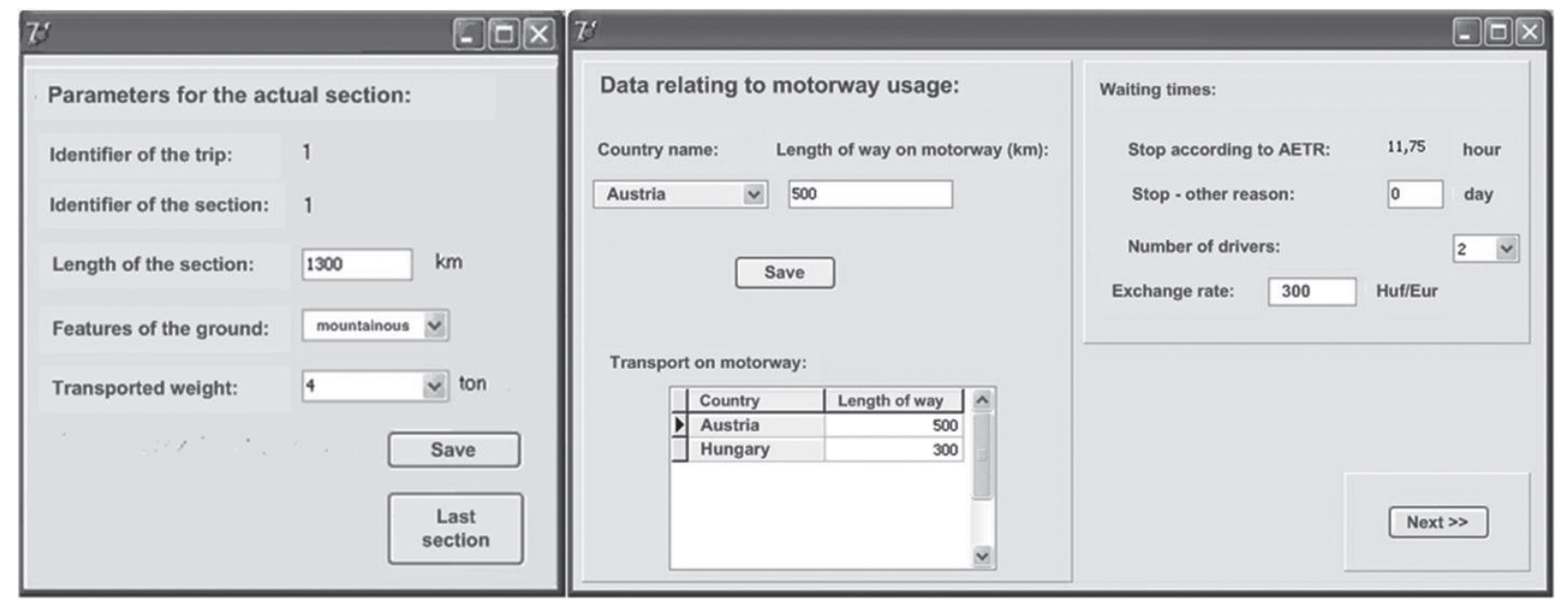

Fig. 4. Parameter settings of the transport order. 


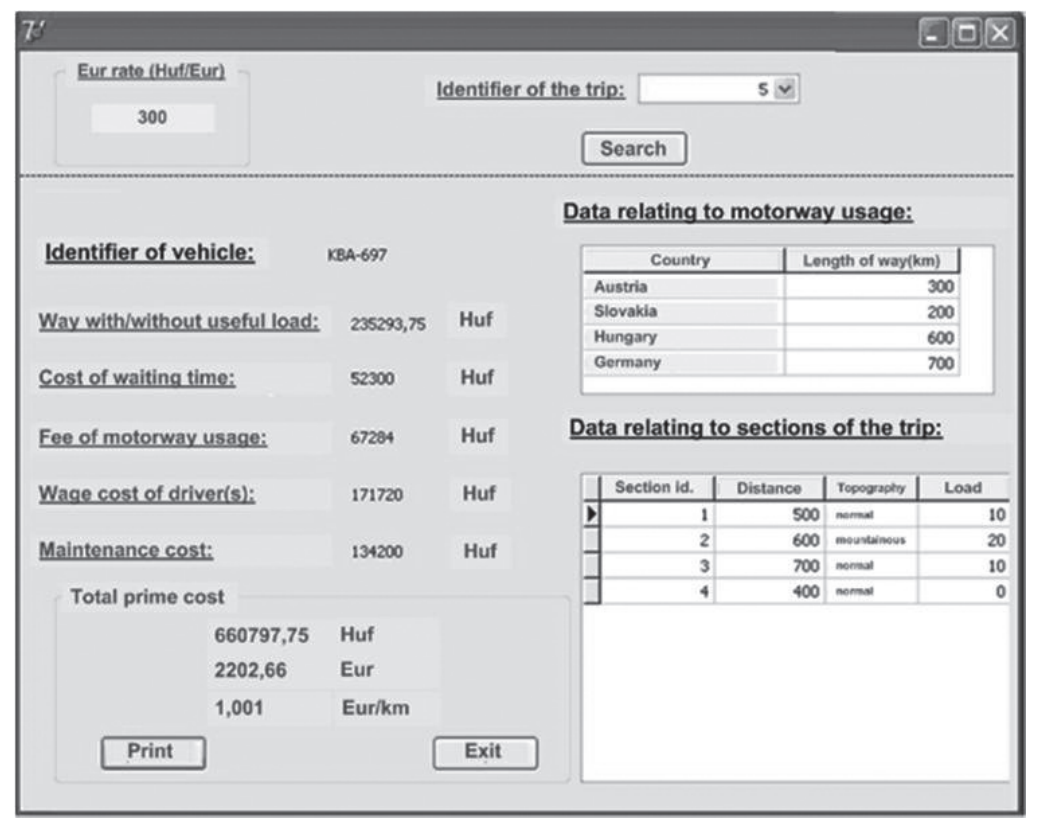

Fig. 5. Calculation results.

Table 1. Comparison of real, calculated and estimated prime costs.

\begin{tabular}{|c|c|c|c|}
\hline & Task 1 & Task 2 & Task 3 \\
\hline 1. Real cost [euro] & 1250 & 1320 & 1845 \\
\hline 2. Calculated cost [euro] & 1215 & 1360 & 1805 \\
\hline 3. Estimated cost [euro] & 1375 & 1235 & 2050 \\
\hline Difference in real cost (1) and calculated cost (2) & $-2.8 \%$ & $+3.0 \%$ & $-2.2 \%$ \\
\hline Difference in real cost (1) and estimated cost (3) & $+10 \%$ & $-6.4 \%$ & $+11.1 \%$ \\
\hline
\end{tabular}

This is a significant difference, therefore resulting in huge losses. This means that the prime costs pre-calculated by the developed method and software are more precise compared to the estimated prime costs. This analysis validates the reliability and precision of the developed prime cost calculation method and software.

\section{Development of Method and Software for Fuel Cost Optimization}

\section{Reason and Goal of the Research}

In recent times in practice, refueling decisions have been made without software at the company, only depending on the subjective decision of the driver, which results in losses.

There are many petrol stations, but the differences between the unit prices of the fuel can be $0.1-0.3$ euro/liter at different stations. Therefore, many times refueling of the vehicle is not carried out at the optimal station (refueling at an expensive petrol station), or the vehicle is not refueled with the optimal amount of fuel (less or more).
The above-mentioned mistakes inspired me to elaborate on a new fuel optimization method for refueling.

The goal of the research is to optimize fuel costs due to different unit fuel prices, first by defining the optimal petrol station, then by determining the optimal volume of refilled fuel.

Firstly, a precise and reliable mathematical model and an optimization method were created to select the optimal petrol station (depending on the unit fuel price and distances between the potential petrol stations and the vehicle). Then determine the optimal amount for refueling (only the required amount of fuel, not less or more) to fulfill transport tasks. Both less and higher amount of fuel refilled results in losses. Less than the optimal amount of refilled fuel results in extra unnecessary refueling. A higher amount of fuel refilled near the end of the route is also a waste, because the cheapest fuel is available at the depot of the carrier.

Then, based on the elaborated optimization method, new decision-supporting software was developed that can lead to significant cost savings. 


\section{Optimization Method for Fuel Cost Reduction}

Total Prime cost Function of a Transport Trip

At first, I had to define the total prime cost function of a transport trip to find the possibilities of cost reduction. The total prime cost of a transport trip can be calculated (same as in Eq. (4)):

$$
C_{P i}=\sum_{j=1}^{N} C_{F i j}+C_{W T i j}+C_{A i j}+C_{W i j}+C_{O i j} \quad \text { [euro] }
$$

Because the aim of optimization is to minimize the fuel cost, the fuel cost component of the transport trip $\left(C_{F i j}\right)$ is examined in detail and the other cost components can be neglected.

The total fuel cost of a transport trip is the sum of the costs of the transport sections:

$$
C_{F i j}=\sum_{j=1}^{N} c_{F i j} \cdot L_{i j} \quad[\text { euro] }
$$

...where $C_{F i j}$ is the specific cost of the section [euro $/ \mathrm{km}$ ] (Eq. (6)) and $L_{i j}$ is the distance of the section [km].

\section{Selecting the Optimal Petrol Station}

The first goal is to determine the optimal (most costeffective) petrol station (Fig. 6) among those preferred by the carrier $\left(T_{i j}\right)$ for a transportation demand from a loadin station $S_{i j}$ to load-out station $S_{i j+1}$ (GPS coordinates of the available petrol stations and the actual fuel prices at the stations are available); and to determine the amount of refilled fuel $\left(Q_{T i j}\right)$ with a known initial level of fuel (Fig. 6).

The fuel level of the transport vehicle is known at the starting load-in station $\left(Q_{f s}\right)$ and the fuel consumption can be calculated continuously (Eq. (6)) between the load-in and load-out stations (Fig. 6).

There is a constraint relating to the amount of safe fuel margin capacity $\left(Q_{S}\right)$ which has to be available. This amount covers the extra consumption of the vehicle resulting from missed ways, congestion, accidents, etc. between load-in station $S_{i j}$ and petrol station $T_{i l}$, and after load-out station $S_{i j+1}$ to find the next petrol station $T_{i m}$ (Fig. 6).

The maximal transport distance $\left(L_{\max }\right)$ that can be completed by a vehicle is calculated as follows (Fig. 6):

$$
L_{\max }^{i j}=\frac{Q_{f_{s}}-Q_{S}}{f_{e}+\varepsilon_{i j}^{T} \cdot f_{e}+\varepsilon^{L} \cdot m_{i j}}[\mathrm{~km}]
$$

The search zone, which is the radius $\left(L_{\max }-\Delta L\right)$, determines the coordinates of possible $T_{i l}$ refilling petrol stations from which the optimal station should be selected (Fig. 6). The value of $\Delta \mathbf{L}$ can be defined relating to the distance from which the optimal petrol station has to be selected before the vehicle runs out of fuel.

Then the optimal refilling station has to be selected that provides the most cost-effective solution.

Total fuel costs of different transport route alternatives can be calculated by (14), based on Fig. 7 .

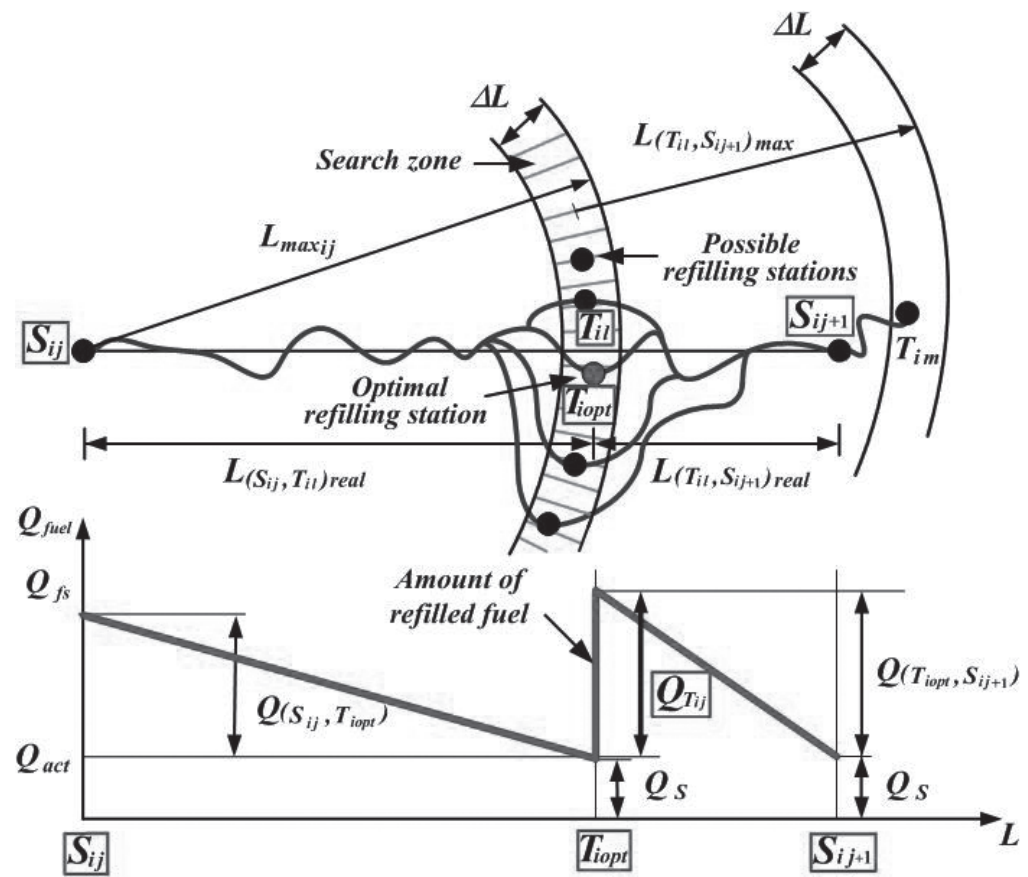

Fig. 6. Determining possible/optimal refilling petrol stations and changes in fuel level during the transport trip. 


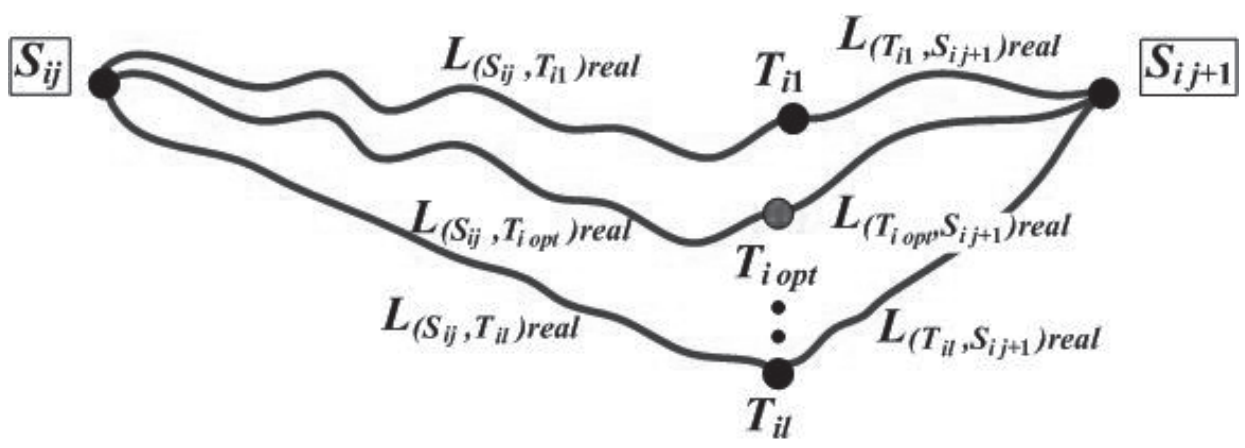

Fig. 7. Route alternatives and selecting optimal refilling petrol stations.

$$
C_{\min }=\min _{i j}\left(c_{\left(S_{i j}, T i l\right)} \cdot L_{\left(S_{i j}, T i l\right) r e a l}+c_{(T i l, S i j+1)} \cdot L_{(T i l, S i j+1) r e a l}\right)
$$

...where $c_{(S i j, T i j)}$ is specific fuel cost taking into consideration the unit fuel price at petrol station before load-in station $S_{i j}$ [euro/km]; $c_{(T i j, S i j+1)}$ is specific fuel cost taking into consideration the unit fuel price at petrol station $T_{i l}$ [euro $\left./ \mathrm{km}\right] ; L_{(S i, T i j) r e a l}$ is transport distance between load-in station $S_{i j}$ and petrol station $T_{i l}[\mathrm{~km}]$; and $L_{(T i j, S i j+1) r e a l}$ is transport distance between petrol station $T_{i l}$ and load-out station $S_{i j+1}[\mathrm{~km}]$.

The optimal transport route defines the optimal petrol station $\left(T_{\text {i opt }}\right)$ that provides a minimal total fuel cost (Eq. (14)).

\section{Determining the Optimal Volume of Refilled Fuel}

The next aim of our research is to calculate the optimal amount (only the required amount of fuel, not less or more) of refilled fuel to complete the transport order. The required amount of refilled fuel $\left(Q_{T i j}\right)$ can be calculated based on Fig. 6:

$$
Q_{T i j}=\left(f_{e}+\varepsilon_{i j}^{T} \cdot f_{e}+\varepsilon^{L} \cdot m_{i j}\right) \cdot L_{(T i o p t, S i j+1) r e a l}+Q_{S}-Q_{a c t}
$$

...where $Q_{S}$ is the safety margin of fuel and $Q_{a c t}$ is the actual fuel level in the vehicle arriving at the defined optimal petrol station.

Software Development for Selecting the Optimal Petrol Station and Determining the Refilling Optimal Volume of Fuel

Based on the elaborated theoretical method, software was developed for optimizing the fuel cost (written in C\# programming language). At first the operation of the software is introduced generally. Then a real case study is also introduced by using the database provided by a carrier. The case study validates that significant cost savings can be realized by the application of the software.

\section{Menu Points of the Developed Software}

1) Menu "Definition of new data".

The user can define new fuel stations, new load-in and load-out stations and new vehicles.

2) Menu "Optimization" (Fig. 8).

- The software provides the possibility of selecting a vehicle for a given transport order. The actual fuel level of the vehicle at the starting point and the unit fuel price of this existing fuel can also be input

(Part 8.a).

In the case study: The selected vehicle is a light truck; fuel consumption is $141 / 100 \mathrm{~km}$; the maximal loading capacity is 3.5 ton; fuel volume at the beginning is $100 \mathrm{l}$; unit fuel price of this existing fuel: $300 \mathrm{HUF} / \mathrm{l}$.

- $\quad$ Part 8.b provides the possibility of defining a road freight transport trip, the load-in and load-out stations and the loading conditions (weight of loading and unloading goods in ton) on the different transport road sections.

In the case study: Station $1:+3$ ton $\rightarrow$ Station 2 : +1.5 ton and -1 ton $\rightarrow$ Station $3:+1.5$ ton and -2 ton $\rightarrow$ Station 4: +1 ton and -1 ton $\rightarrow$ Station $5:+1$ ton and -2 ton $\rightarrow$ Station 6: +2.5 ton and $-1,5$ ton $\rightarrow$ Station $7:+0$ ton and -1 ton $\rightarrow$ Station 1: -2 ton (see map of Part 8.d.).

- The results of the fuel supply optimization are listed on Part 8.c. The total cost and distance of the road freight transport trip, the total fuel consumption of the trip and the remaining fuel volume at the end of the transport trip are listed.

In the case study: The total cost of the transport trip is 50800 HUF; the total volume of fuel consumption is $161.9 \mathrm{l}$; the remaining safety fuel is 111 .

- The route of the transport trip and the coordinates of the optimal petrol station for refueling are depicted on a map in Part 8.d.

In the case study: The route of the transport trip is station 1-7; the location of the optimal petrol station is in the search zone (red rectangle on the map).

- Part 8.e shows the identifier and location of the optimal refilling station. The optimal volume of fuel to be refilled is also listed. The actual unit fuel price at the optimal refilling station and the total cost of the fuel to be refilled are also listed. 


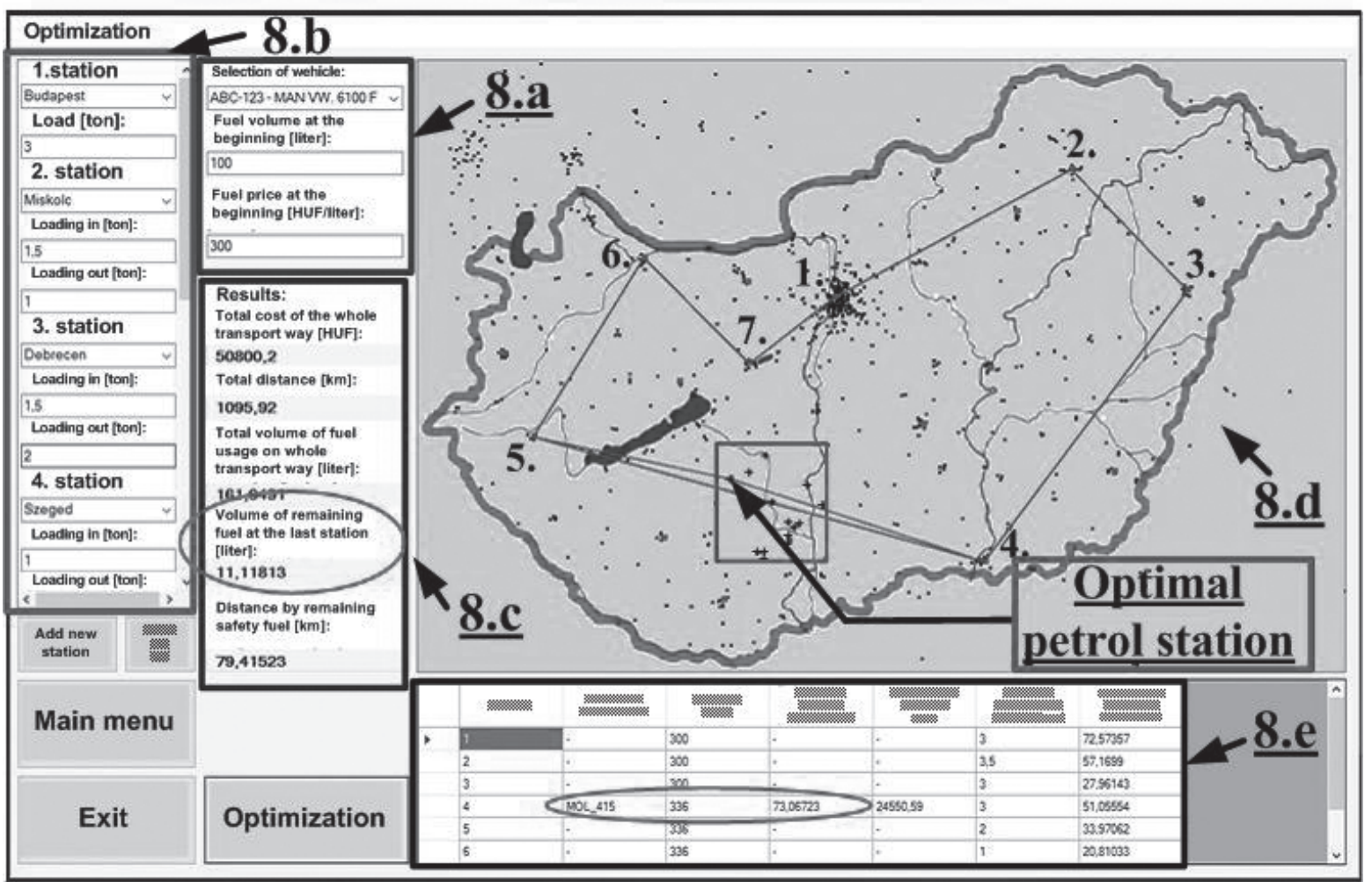

Fig. 8. "Optimization" screen.

In the case study: The optimal petrol station is the MOL 415; the amount of refilled fuel is 731 ; the minimal unit fuel price is $336 \mathrm{HUF} / 1$.

\section{Results of the Software Application}

By the application of the developed software, in the case study $15.85 \%$ cost savings can be attained compared the data calculated by the software (optimal decision) to the driver's wrong decision based on estimation. The reason for the driver's wrong decision is that the driver refueled at the most expensive petrol station in the search zone and refueled with an unnecessarily high amount of fuel.

Result of the method and software: increasing the profit at the company by reducing fuel costs. By the application of software the vehicle drivers can make the best refueling decision and the total fuel cost of the transport trip can be minimized.

\section{Conclusions}

Nowadays globalization, market competition and growing environmental damage require road freight transportation to be not only cost-effective and profitable, but at the same time sustainable and environmentally friendly. Optimization and efficiency improvement of the freight transport activity on the one hand is essential for transport companies to maintain and increase their competitiveness, on the other hand to automatically reduce fuel consumption and environmental damage, therefore supporting the sustainable freight transportation.

This research is actual and important because environmentally friendly and sustainable freight transportation has become an important research field.

This goal can be reached only by competitive and profitable transport companies, which are able to reduce transport costs and optimize their transport processes. If a company is able to make higher profits, then it can afford to invest in environmentally friendly technologies and new fleets of vehicles, which results in reduced environmental damage.

The study introduced three new and innovative theoretical methods and three original decisionsupporting software applications that were developed for optimizing road freight transport activities, thus providing economical, sustainable and environmentally friendly freight transportation:

1) Structure of KPIs and software - efficiency improvement of transport processes by continuous performance measurement and evaluation. If we can measure the historical and current performance of transport activities, we can improve the efficiency of the processes in the future.

I elaborated on the four most important and commonly used transport indicators (transport method utilization, time utilization, weight of transported goods, and fuel consumption) relating to individual vehicles, vehicle groups, all of vehicles and transport 
trips. The software application is able to evaluate indicators for a selected examination time interval numerically and graphically.

2) Calculation method and software - ensure the profitability of the company. The method and the software determine precisely and quickly the total prime cost of a given road freight transport order. This is very important, because if the prime cost can be defined precisely before the carrier gives a quotation to the customer, the carrier can calculate the expected profit. As the transport fee includes the expected profit, it can be ensured and losses can be eliminated.

3) Optimization method and software - increase profit by reducing costs.

The method and the software optimize the fuel cost of the transport activity both by selecting the optimal petrol station (most cost-effective, depending on the unit fuel price and distance of the potential petrol stations), and by determining the optimal amount of refilled fuel (needed to complete the given transport order, including a certain safety amount of fuel to cover unexpected events, e.g., missed ways, congestion, accidents, etc.).

The fuel cost reduction resulting from applying the developed calculation method and software (optimal decision) was validated in a case study by comparing the driver's wrong decision based on estimation.

Recently in practice the previously described activities are unsupported by software, therefore the three newly introduced software applications are innovative and original. The software applications support the establishment of cost-effective, sustainable and environmentally friendly transportation.

The developed software applications absolutely meet the companies' demands, are easy to use, and can be used widely in practice because they are very costeffective and therefore suitable also for SMEs.

The 3 developed software applications have been successfully implemented by carriers.

\section{Conflict of Interest}

The authors declare no conflict of interest.

\section{References}

1. KOVÁCS GY., KOT S. New logistics and production trends as the effect of global economy changes. Polish Journal of Management Studies, 14 (2), 115, 2016.

2. FRAUNHOFER INSTITUTE. Executive summary. http:// www.scs.fraunhofer.det (accessed on 15 March 2018).
3. MIOMIR M.J. Belgrade's urban transport $\mathrm{CO}_{2}$ emissions from an international perspective. Polish Journal of Environmental Studies, 25 (2), 635, 2016.

4. JIE-FANG D., JIE-YU H., RONG-WEI W., CHUN D. Delinking Indicators on Transport Output and Carbon Emissions in Xinjiang, Polish Journal of Environmental Studies, 26 (3), 1045, 2017.

5. COOK W.D., ZHU J. Modeling performance measurement, Springer, 2005.

6. ROSS D.F. Distribution planning and control, managing in the era of supply chain management, Springer, 2015.

7. SINHA K.C., LABI S. Transportation decision making, John Wiley \& Sons Inc, 2007.

8. WOXENIUS J. Directness as a key performance indicator for freight transport chains. Research in Transportation Economics, 36 (1), 63, 2012.

9. POTKÁNY M., KRAJČ́́ROVÁ L. Cost reporting of the transport company and its use in decision making. Procedia Engineering, 192, 731, 2017.

10. TEODOROVIĆ D., JANIĆ M. Transportation engineering, Butterworth-Heinemann, 2017.

11. RUSHTON A., CROUCHER P., BAKER P. The handbook of logistics \& distribution management, Kogan Page Limited, 2010.

12. CHATZIKONTIDOU A., LONGINIDIS P., TSIAKIS P., GEORGIADIS M.C. Flexible supply chain network design under uncertainty. Chemical Engineering Research and Design, 128, 290, 2017.

13. ROSTAMZADEH R., SABAGHI M., SOFIAN S., ISMAIL Z. Hybrid GA for material routing optimization in supply chain. Applied Soft Computing, 26, 107, 2015.

14. GUDEHUS T., KOTZAB H. Comprehensive logistics, Springer, 2009.

15. BOKOR Z. Improving transport costing by using operation modeling. Transport, 26 (2), 128, 2011.

16. CARAMIA M., DELL'OLMO P. Multi-objective management in freight logistics, Springer, 2008.

17. DINU S., BODEA G. A new genetic approach for transport network design and optimization. Bulletin of the Polish Academy of Sciences Technical Sciences, 59 (3), 263, 2011.

18. EHMKE J.F. Integration of information and optimization models for routing in city logistics, Springer, 2012.

19. SIMCHI-LEVI D., XIN C., BRAMEL J. The logic of logistics, theory, algorithms, and applications for logistics management, Springer, 2014

20. ANBUUDAYASANKAR S.P., GANESH K., MOHAPATRA S. Models for practical routing problems in logistics. Design and practices. Springer, 2014.

21. DANCHUK V., BAKULICH O., SVATKO V. An improvement in ant algorithm method for optimizing a transport route with regard to traffic flow. Procedia Engineering, 187, 425, 2017.

22. KOCA C., LAPORTE G. Vehicle routing with backhauls: Review and research perspectives. Computers \& Operations Research, 91, 79, 2018.

23. IBARRA-ROJAS O.J., HERNANDEZ L., OZUNA L. The accessibility vehicle routing problem. Journal of Cleaner Production, 172, 514, 2018 
